\title{
Clinical Study Lead Organization
}

National Cancer Institute

\section{Source}

National Cancer Institute. Clinical Study Lead Organization. NCI Thesaurus. Code C70790.

An org anization responsible for the overall scientific and administrative coordination,

study monitoring, and data management activities of a particular clinical trial. 